Saba H Al-Zubaidi BDS, MSc (Lec.)

\section{The Effect of Insertion Angle on Primary Stability of Orthodontic Mini-implants "An Experimental in vivo Study"}

\author{
Dept of Pedod, Orthod, and Prev Dentistry
}

College of Dentistry, University of Mosul

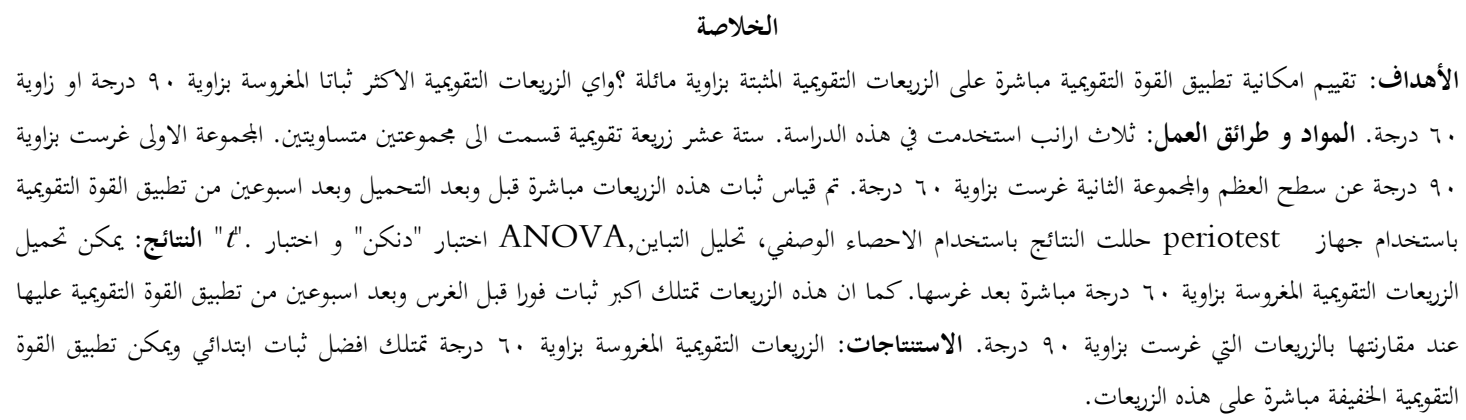

\title{
ABSTRACT
}

Aims: To determine whether obliquely inserted mini-implants can be loaded immediately with light orthodontic force? And which mini-implants are more stable those with 90 degree or 60 degree insertion angles? Materials and Methods: three rabbits were used in this study. Sixteen mini-implants divided into 2 groups equally. The first group implanted in the rabbit's tibia bone at 90 degree insertion angle and the second group implanted in the rabbit's tibia bone at 60 degree insertion angle. The stability of mini-implants was measured using periotest device immediately before and after loading and after 2 weeks of loading period. The data were analyzed using descriptive statistic, Analysis of variance (ANOVA), Duncan Multiple analysis range test and student $t$-test. Result: mini-implants at 60 degree insertion angle can be loaded immediately with light orthodontic force. Also, those miniimplants having a significant greater stability before loading and after two weeks of loading period in comparison with mini-implants implanted at 90 degree angle. Conclusions: In clinical practice, miniimplants inclined to the bone surface at 60degree tend to have better primary stability and can be loaded immediately.

Key words: Orthodontic mini- implant, insertion angle, primary stability.

Al-Zubaidi SH . The Effect of Insertion Angle on Primary Stability of Orthodontic Mini-implants "An Experimental in vivo Study". Al-Rafidain Dent J. 2013; 13(2): 327-332.

Received: $2 / 5 / 2012 \quad$ Sent to Referees: $2 / 5 / 2012$

Accepted for Publication: 6/6/2012

\section{INTRODUCTION}

Before any orthodontic tooth movement is initiated, a precise analysis of the patient's anchorage situation must take place. ${ }^{(1)}$ Orthodontic mini-implants have been proven to facilitate temporary stationary anchorage. ${ }^{(2,3)}$ Mini screws need to achieve adequate primary stability immediately after their insertion, so that they can be healed properly and be loaded immediately. ${ }^{(4)}$ The quality of bone, implant design and the insertion technique are the essential factors influencing primary stability. ${ }^{(5)}$ The most frequently used insertion site is the alveolar ridge. However, tooth injury represents a risk and should not underestimated..$^{(6-8)}$ To avoid root damage, Park et al. ${ }^{(9)}$ introduce an oblique instead of a perpendicular miniimplant insertion because more space was available near the apical region.

So, the aims of the present study were to determine whether obliquely inserted mini-implants can be loaded immediately with light orthodontic force? And which mini-implants are more stable those with 90 degree or 60 degree insertion angles?

\section{MATERIALS AND METHODS}

The experimental mean used in this study was 16 mini-implants (AbsoAnchor System, Dentos, Inc., Daegu, Korea) (1.3mm diameter, $5 \mathrm{~mm}$ length) implanted in the tibia bone of 3 rabbits. These miniimplants divided into 2 groups equally, the 
first group implanted in the rabbit's tibia bone at 90 degree angle to the bone surface, the second group implanted at 60 degree angle to the bone surface. Then these mini-implants subjected to immediate loading (100g of force) using NiTi closed-coil spring (Dentarum) applied to the coronal portion of miniimplants using tension gauge (Anthogyr company, francey). The stability of these mini-implant were measured immediately before and after force application and after 2 weeks of loading period using periotest device (Medizintechnik gulden e.k, Eschenweg 3,64397 modautal, Germany).

Surgical procedure

The operation was carried out under sterile condition. After anaesthetizing the rabbits intramuscularly with ketamine (44 $\mathrm{mg} / \mathrm{kg}$ ) and xylozine $(7 \mathrm{mg} / \mathrm{kg})$, the internal surface of tibia was further blocked with $0.5 \mathrm{ml}$ of $2 \%$ lidocaine. The tibia bone was exposed (Figure 1).

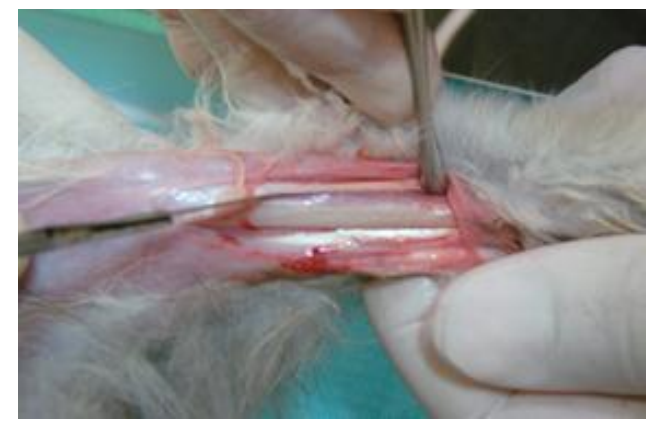

Figure (1):Tibia bone surface.

The cortical bone was penetrated using $0.6 \mathrm{~mm}$-diameter drill under profuse irrigation (Figures 2,3).

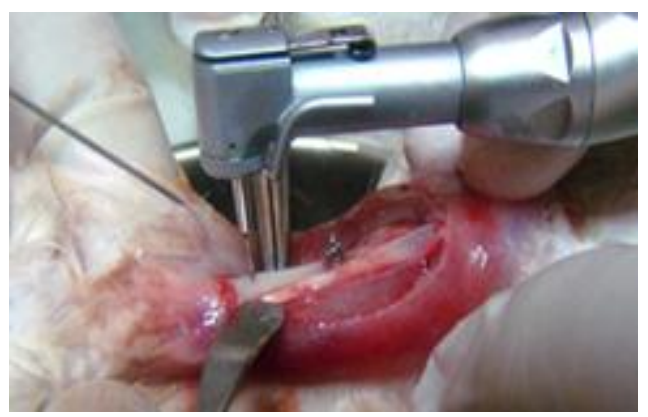

Figure (2): Predrilling at $90^{\circ}$ angle.

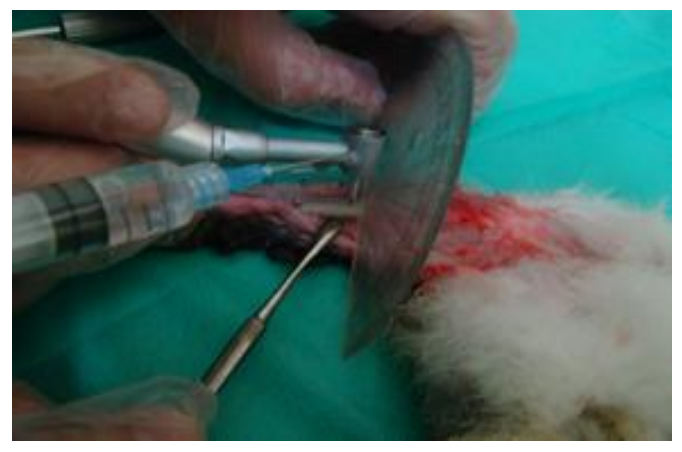

Figure (3): Predrilling at $60^{\circ}$ angle.

Eight of mini-implants were implanted (using a manual driver) at 90 degree angle to the bone surface and the other miniimplants implanted at approximately 60 degree angle to the long axis of the bone surface. The angles were arbitrarily fixed using an angled board ${ }^{(10)}$ (Figures 4,5).

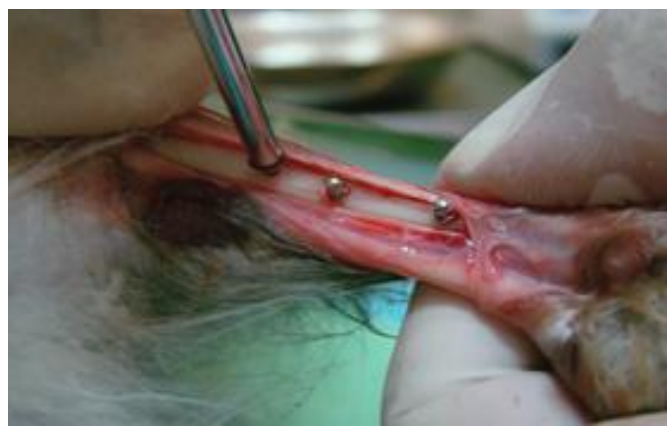

Figure (4): Implantation at $90^{\circ}$ angle.

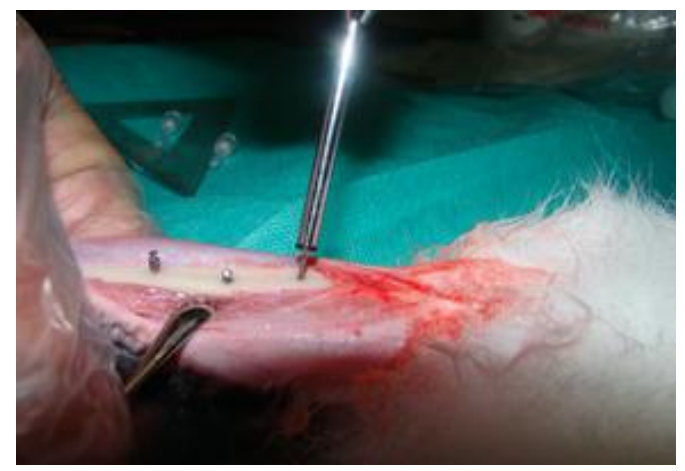

Figure (5): Implantation at $60^{\circ}$ angle.

Then loading them with NiTi closed coil spring applied to the coronal portion of mini-implant (Figures: 6,7). The mucoperiosteum and muscle were sutured using absorbable sutures. 


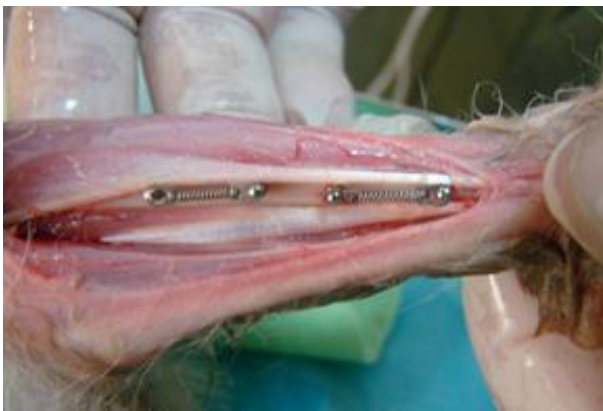

Figure (6): Loading the mini-implants Implanted at $90^{\circ}$ angle.

The data were analyzed using Descriptive statistic, analysis of variance (ANOVA) at $p \leq 0.05$. These data were analyzed by Duncan multiple analysis range test to locate the significant differences among the groups and student $t$-test was also used.

\section{RESULTS}

The descriptive statistic, Duncan multiple analysis range test and F-value for the stability of mini-implant inserted at 90 degree and 60 degree angle to the tibia's bone surface was presented in Table (1) and (2).

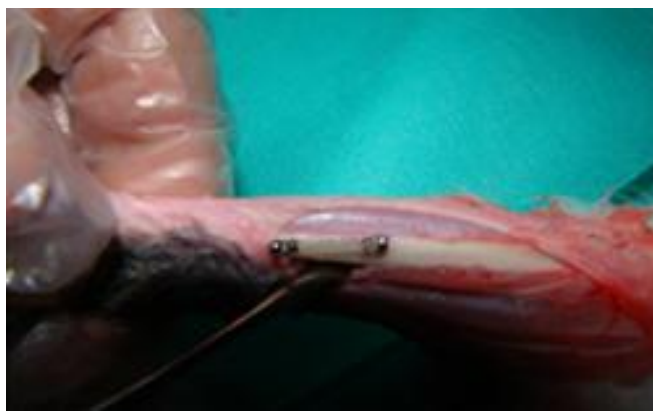

Figure (7): Loading the mini-implants Implanted at $60^{\circ}$ angle.

For the mini-implants with 90 degree insertion angle as shown in Table (1), there was a significant greater stability before loading then immediately after loading and the least stability showed after 2 weeks of loading period.

While for the mini-implants with 60 degree insertion angle as shown in Table (2), there was a significant greater stability immediately after loading, then the stability of mini-implants before loading was greater than the stability of the miniimplants after 2 weeks of loading period but statistically not significant.

Table (1): Descriptive statistic and ANOVA analysis and Duncan Multiple analysis Range test for the stability of mini-implants implanted at 90 degree angle.

\begin{tabular}{cccccc}
\hline Variable & means & $\mathbf{\pm S D}$ & F-value & Sig. & Duncan's group \\
\hline I & 0.612 & 0.112 & & & $\mathrm{~A}$ \\
II & 0.725 & 0.138 & 17.628 & $0.000^{*}$ & $\mathrm{~B}$ \\
III & 0.925 & 0.046 & & & $\mathrm{C}$ \\
\hline
\end{tabular}

*I=the stability of mini-implant before loading; II= the stability of mini-implant immediately after loading; III $=$ the stability of mini-implant after 2 weeks of loading. $* *=$ significant at $p \leq 0.05$.

Table (2): Descriptive statistic and ANOVA analysis and Duncan Multiple analysis Range test for the stability of mini-implants implanted at 60 degree angle.

\begin{tabular}{llllcc}
\hline Variable & means & $\mathbf{\pm S D}$ & $\mathbf{F}$-value & Sig. & Duncan's group \\
\hline I & 0.725 & 0.046 & & & $\mathrm{~A}$ \\
II & 0.663 & 0.074 & 7.764 & $0.003^{*}$ & $\mathrm{~B}$ \\
III & 0.775 & 0.046 & & & $\mathrm{~A}$ \\
\hline
\end{tabular}

*I=the stability of mini-implant before loading; II= the stability of mini-implant immediately after loading; III = the stability of mini-implant after 2 weeks of loading. $* *=$ significant at $p \leq 0.05$. 
In Table (3), the student $t$-value for the stability of the two groups of miniimplants showed that there was a significant greater stability of the miniimplants inserted at 60 degree angle both before loading and after 2 weeks of loading period. For the stability of the mini-implants immediately after loading, although there was no significant differences between the two groups, but the mini-implants with 60 degree insertion angle still having the greater stability.

Table (3): Descriptive statistic and student t-test for the stability of mini-implants of the two groups at different loading times.

\begin{tabular}{lccccc}
\hline Variable & \multicolumn{1}{c}{ Angulation** } & Mean & $\mathbf{\pm S D}$ & $\boldsymbol{t}$-value & Sig. \\
\hline I & 90 & 0.612 & 0.112 & -2.614 & $0.020^{* * *}$ \\
& 60 & 0.725 & 0.046 & & \\
II & 90 & 0.725 & 0.138 & 1.122 & 0.281 \\
& 60 & 0.663 & 0.074 & & \\
III & 90 & 0.925 & 0.046 & 6.481 & $0.000^{* * *}$ \\
& 60 & 0.775 & 0.046 & & \\
\hline
\end{tabular}

*I=the stability of mini-implant before loading; II= the stability of mini-implant immediately after loading; III = the stability of mini-implant after 2 weeks of loading., $* *=$ the variable measured in degree, $* * *=$ significant at $p \leq 0.05$.

\section{DISCUSSION}

One of the methods used to measure implant stability is by using periotest device (Figure 8). This instrument was developed to measure the degree of periodontal integration of tooth and the stiffness of the bone/implant interface in oral implantology. ${ }^{(11)}$

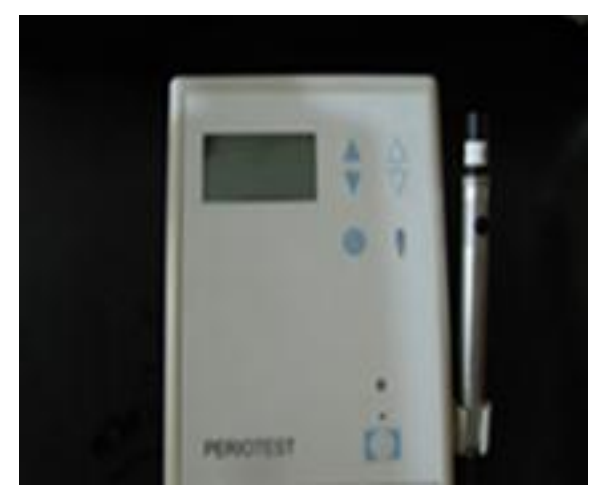

Figure (8): Periotest device.

To avoid root injury, some clinicians have advised inserting the mini-implants at different angulations. Many authors ${ }^{(12-15)}$ suggested that 30-45degree insertion angles of mini-implants were preferable. While others ${ }^{(8,16)}$ suggested that insertion angles between 60-70 degree were associated with greater stability.

The mini-implants with 90 degree insertion angle can be loaded immediately with light orthodontic forces. Also, the inclined orthodontic mini-implants can be loaded immediately with light orthodontic force with good stability which come in agreement with other studies. ${ }^{(10,17)}$

Even though the insertion depth of the mini-implants was lesser after an oblique insertion than after a perpendicular insertion, the highest stability was measured when the mini-implants were inserted obliquely at 60 degree angle. The reason of this result may be due to a longer distance through cortical bone when the mini-implants were inserted in an oblique direction than in a perpendicular direction. The result of this study comes in agreement with other studies. ${ }^{(18-21)}$

Cortical bone is, by nature, much more dense than cancellous bone, therefore, the threads of the mini-implants are in more intimate contact with the cortical bone, enhancing primary stability. ${ }^{(22)}$

But this study disagrees with Jasmine etal., study, ${ }^{(23)}$ they inserted mini-implants 
at 30, 45, 60 and 90 degree to the bone surface, they stated that placement of micro implants at 90 degree angulation in the bone reduces the stress concentration, thereby increasing the likelihood of implant stabilization. The reason for this difference may be due to difference in the sample size.

For both groups of mini-implants, the greater stability occurred immediately after implantation of the mini-implants in rabbit's tibia bone and the stability decrease after two weeks. The greater immediate stability was due to mechanical retention (primary stability), and the decreased in the stability after two weeks may be due to the temporary inflammatory reaction due to insertion trauma.

\section{CONCLUSIONS}

According to this study, to achieve the best primary stability, an insertion angle of the mini-implants at 60 degree rather than at 90 degree is advisable. If the available space between two adjacent roots is small, a more oblique direction of insertion seems to be favorable to minimize the risk of root contact.

\section{REFERENCES}

1. Stahl E, Keilig L, Abdelgader I, Jager A and Bourauel C. Numerical analysis of biomechanical behavior of various orthodontic anchorage implants. $J$ Orofacial Orthop. 2009;70:115-270.

2. Cope JB. Temporary anchorage devices in orthodontics. A paradigm shift. Semin Orthod. 2005;11:3-9.

3. Ludwig B, Böhm B. Mini-implantate in der kieferorthopädie: innovative verankerungs konzepte. Berlin: Quintessenz Verlags-Gmblt. 2007.

4. Shah AH. Effect of miniscrew characteristics (length and outer diameter) and bone properties (cortical thickness and density) on insertion torque and pullout strength. Master thesis, Saint Louis University. 2011.

5. Wilmes B, Rademacher C, Olthoff G, Drescher D. Parameters affecting primary stability of orthodontic mini-implants. $J$ Orofacial Orthop. 2006; 67(3):162-174.

6. Fabbron G, Aabed S, Mizen K, Starr DG. Transalveolar screws and the incidence of dental damage: a prospective study. Int $J$
Oral Maxillofacial Surg. 2004;33:442446.

7. Asscherickx K, Vannet BV, Wehrbein H, Sabzevar MM. Root repair after injury from mini-screw. Clin Oral Implants Res.2005;16:575-578.

8. Wilmes B, Su YY, Sadigh L, Drescher D. Predrilling force and insertion torques during orthodontic mini-implant insertion in relation to root contact. J Orofacial Orthop. 2008; 69:51-58.

9. Park HS, Bae SM, Kyung HM, Sung JH. Micro-implant anchorage for treatment of skeletal Class I bialveolar protrusion. $J$ Clin Orthod. 2001; 35:417-422.

10.Inaba M. Evaluation of primary stability of inclined orthodontic mini-implants. J Oral Science. 2009; 51(3):347-353.

11.Winkler S, Morris HF, Spray JR. Stability of implants and natural teeth as determined by the periotest over 60 months of function. J Oral Implantol. 2001;27:198-203.

12.Carano A, Velo S, Leone P, Siciliani G. Clinical applications of the miniscrew anchorage system. $J$ Clin Orthod. 2005;39:9-24.

13. Kyung HM, Park HS, Bae SM, Sung JH, Kim IB. Development of orthodontic micro-implants for intra oral anchorage. $J$ Clin Orthod. 2003; 37:321-328.

14.Lim J, Lim WH, Chun YS. Quantitative evaluation of cortical bone thickness and root proximity at maxillary inter radicular sites for orthodontic mini-implant. Clinical anatomy, New York NY. 2008;21(6):486491.

15. Noble J, Karaiskos NE, Hassard TH, Hechter FJ, Wiltshire WA. Stress on bone from placement and removal of orthodontic miniscrews at different angulation. $J$ Clin Orthod. 2009; XLIII(5):332-334.

16. Wilmes B, Su YY. Insertion angle impact on primary stability of orthodontic miniimplants. Angle Orthod. 2008b; 78(6):1065-1069.

17.Takano-Yamamoto T, Miyawaki S, Koyama I. Can implant orthodontics change the conventional orthodontic treatment? Dental Diamond. 2002; 27: 2647.

18.HujaSS, Litsky AS, Beck FM, Johnson KA, Larsen PE. Pull-out strength of monocortical screws placed in the 
maxillae and mandibles of dogs. Am $J$ Orthod Dentofacial Orthop. 2005; 127: 307-313.

19.Motoyoshi M, Yoshida T, Ono A, Shimizu $\mathrm{N}$. Effect of cortical bone thickness and implant placement torque on stability of orthodontic mini-implants. Int J Oral Maxillofac Implants. 2003; 124: 373-378.

20.Deguchi T, Nasu M, Murakami K, Yabuuchi T, Kamioka H, TakanoYamamoto T. Quantitative evatuation of cortical bone thickness with computed tomographic scanning for orthodontic implants. Am $J$ Orthod Dentofacial Orthop. 2006; 129(6): 721.

21.Quan D, Jiang-hao C, Hong Z. The influence of micro-implant insertion angle on the stability of micro-implant. Chinese $J$ of Aesthetic Medicine. 2009.

22.Micah GM. Comparison of stability of 3 and $6 \mathrm{~mm}$ miniscrew implants immediately-loaded with two different force levels in the beagle dog. Master thesis. Saint Louis University. 2007.

23.Jasmine IF, Yezdani AA, Tajir F, Venu RM. Analysis of stress in bone and micro implants during en-masse retraction of maxillary and mandibular anterior teeth with different insertion angulations: A3dimensional finite element analysis study. Am J Orthod Dentofacial Orthop. 2012; 141(1): 71-80. 